\title{
SISTEM ANALISIS GAYA BELAJAR MENGGUNAKAN ALGORITMA K-NEAREST NEIGHBOUR
}

\author{
Sulton Ginanjar Abdullah ${ }^{[1]}$, Rawansyah ${ }^{[2]}$, Dyah Ayu Irawati ${ }^{[3]}$ \\ Program Studi Teknik Informatika Jurusan Teknik Elektro Politeknik Negeri Malang \\ sulton.ginanjar@gmail.com ${ }^{[1]}$, rawansyah@yahoo.com ${ }^{[2]}$, dyah.ayu@polinema.ac.id ${ }^{[3]}$
}

\begin{abstract}
Abstrak
Gaya belajar adalah cara atau kebiasaan yang dilakukan individu dalam menyerap, memproses, dan mengelola informasi. Gaya belajar merupakan faktor penting yang menunjang bagi tercapainya tujuan pembelajaran. Tipe gaya belajar ada tiga yaitu visual, auditori dan kinestetik. Tipe visual belajar melalui apa yang mereka lihat. Tipe auditori belajar melalui apa yang mereka dengar. Sedangkan tipe kinestetik belajar malalui gerak, emosi dan sentuhan. Tujuan dari penelitian ini adalah membuat aplikasi untuk menganalisis gaya belajar seseorang sehingga dapat diketahui gaya belajar dan cara belajar yang tepat untuk individu tersebut. Cara belajar merupakan penerapan dari tipe gaya belajar yang telah diketahui, sehingga memudahkan seseorang dalam proses belajarnya. Metode yang digunakan adalah membandingkan training data set dengan data uji yang kemudian diolah menggunakan algoritma K-Nearest Neighbour (KNN) dalam proses data mining untuk menganalisis gaya belajar. Training data set yang digunakan dalam sistem ini merupakan data hasil tes gaya belajar yang dihasilkan oleh Bela Hening Hukama (2011), yang di dalamnya terdapat parameter-parameter tipe gaya belajar. Algoritma K-Nearest Neighbour merupakan pendekatan untuk mencari kasus baru dengan kasus lama, yaitu berdasarkan pada pencocokan bobot dari sejumlah fitur yang ada. Hasil dari penelitian ini adalah aplikasi analisis gaya belajar berdasarkan pernyataan-pernyataan yang berisi parameter gaya belajar yang sudah ditentukan yang dapat menentukan gaya belajar yang tepat dengan akurasi 88\%. Kesimpulan dari penelitian ini adalah algoritma $K$-Nearest Neighbour dapat diimplementasikan dalam kasus ini dengan akurasi yang paling optimal sebesar $88 \%$, yaitu pada $\mathrm{K}=9$. Error banyak terjadi pada parameter yang merupakan kombinasi dari beberapa tipe gaya belajar, dan error terbesar yaitu pada parameter kombinasi visual, auditori dan kinestetik.
\end{abstract}

\section{Kata Kunci : Data Mining, Gaya Belajar, K-Nearest Neighbour, KNN}

\section{Pendahuluan}

Mengacu pada Undang-Undang Nomor 20 tahun 2003 tentang Sistem Pendidikan Nasional Pasal 3 bahwa tujuan pendidikan nasional adalah mengembangkan potensi peserta didik agar menjadi manusia yang beriman dan bertakwa kepada Tuhan Yang Maha Esa, berakhlak mulia, sehat, berilmu, cakap, kreatif, mandiri, dan menjadi warga negara yang demokratis serta bertanggung jawab. Untuk mewujudkan tujuan pendidikan nasional ini diperlukan perangkat pengajaran yang memadai untuk menunjang pendidikan yang berkualitas. Salah satu cara untuk menggali potensi peserta didik adalah mengajarkan materi sesuai dengan gaya belajar siswa agar ilmu yang mereka serap bisa maksimal. Gaya belajar adalah cara atau kebiasaan yang dilakukan individu dalam menyerap, memproses, dan mengelola informasi. Untuk menjawab pertanyaan ini, diperlukan sebuah sistem untuk menganalisis gaya belajar yang dapat menentukan gaya belajar yang tepat.

\section{Metode}

a. Metodologi

Metode yang akan digunakan dalam penelitian ini terdiri dari langkah-langkah berikut:

- Melakukan studi kepustakaan terhadap berbagai referensi yang berkaitan dengan penelitian yang dilakukan. Topik-topik yang akan dikaji antara lain meliputi : gaya belajar, analisis gaya belajar, data mining, klasifikasi dalam data mining, dan algoritma KNN.

- Menyiapkan training data set yang akan digunakan untuk proses pembelajaran dari sistem.

- Merancang sistem analisis gaya belajar kemudian membuat aplikasinya dengan bahasa pemrograman Visual Basic 2010 dan database SQL Sever 2008.

- Melakukan pegujian terhadap sistem analisis gaya belajar siswa.

b. Data Mining

Metode yang digunakan untuk memecahkan permasalahan ini adalah dengan proses data mining. 
Kesimpulan ditentukan dari hasil perbandingan training data set dengan data uji yang diolah dengan algoritma K-Nearest Neighbour. Data mining merupakan proses pencarian pola-pola yang menarik dan tersembunyi (hidden pattern) dari suatu kumpulan data yang berukuran besar yang tersimpan dalam suatu basis data, data warehouse, atau tempat penyimpanan data lainnya (Tan dkk 2006).

c. Algoritma K-Nearest Neighbour

Algoritma K-Nearest Neighbour adalah

pendekatan untuk mencari kasus baru dengan kasus lama, yaitu berdasarkan pada pencocokan bobot dari sejumlah fitur yang ada. Misalkam diinginkan untuk mencari solusi terhadap seorang pasien baru dengan menggunakan solusi dari pasien terdahulu (Kusrini dan Emha Taufiq Lutfhi, 2009). Untuk menghitung jarak antara 2 objek klasifikasi, dapat menggunakan fungsi distance sebagai berikut (Kardi Teknomo, 2006) :

$$
\begin{aligned}
& \text { Absolute Distance: } \\
& \mathrm{d}(x, y)=\sum_{i=0}^{n}\left(\sqrt{|x i-y i|^{2}}\right)
\end{aligned}
$$

Persamaan 2.1

Euclediean Distance:

$$
\mathrm{d}(x, y)=\sum_{i=0}^{n}\left(\sqrt{x i^{2}-y i^{2}}\right)
$$

Persamaan 2.2

Semakin besar jarak yang dihasilkan, maka akan semakin jauh tingkat keserupaan antara kedua objek. Sebaliknya, semakin kecil jarak euclediean maka akan semakin dekat tingkat keserupaan kedua objek tersebut.

Tahapan untuk menentukan klasifiksi berdasarkan algoritma K-Nearest Neighbour dijabarkan oleh Kardi Teknomo (2006) sebagai berikut :

Pertama ditentukan data set yang digunakan untuk data uji, dalam kasus ini, digunakan dua atribut yaitu ketahanan asam yang disimbolkan dengan $\mathrm{X}_{1}$ dan kekuatan yang disimbolkan dengan $\mathrm{X}_{2}$. Contoh data latih ada pada table 2.1.

Tabel 2.1 Contoh data latih

\begin{tabular}{|c|c|c|}
\hline $\begin{array}{l}\text { X1 } \\
\text { Ketahanan } \\
\text { Asam } \\
\text { (detik) }\end{array}$ & $\begin{array}{l}\text { X2 } \\
\text { Kekuatan } \\
(\mathrm{Kg} / \mathrm{m} 2)\end{array}$ & Klasifikasi \\
\hline 7 & 7 & Buruk \\
\hline 7 & 4 & Buruk \\
\hline 3 & 4 & Baik \\
\hline 1 & 4 & Baik \\
\hline
\end{tabular}

Data baru yang akan diuji $\mathrm{X}_{1}=3$ dan $\mathrm{X}_{2}=7$, setelah itu ditentukan nilai parameter dari $\mathrm{K}$ sebagai jumlah tetangga yang paling dekat. Dalam kasus ini, nilai $\mathrm{K}$ adalah 3. Mengkalkulasikan jarak antara query instance dan semua contoh pelatihan seperti pada table 2.2 dengan menggunakan rumus Absolute Distance untuk menghitung jarak $\mathrm{X}_{1}$ dan $\mathrm{X}_{2}$ untuk menggolongkan apakah suatu kertas tisu baik atau tidak.

Tabel 2.2 Perhitungan query instance

\begin{tabular}{|c|c|l|}
\hline $\begin{array}{l}\text { X1 } \\
\text { Ketahanan } \\
\text { Asam } \\
\text { (detik) }\end{array}$ & $\begin{array}{l}\text { X2 } \\
\text { Kekuatan } \\
(\mathrm{Kg} / \mathrm{m} 2)\end{array}$ & $\begin{array}{l}\text { Kuadrat Absolute } \\
\text { Distance }(3,7)\end{array}$ \\
\hline 7 & 7 & $(7-3) 2+(7-7) 2=16$ \\
\hline 7 & 4 & $(7-3) 2+(4-7) 2=25$ \\
\hline 3 & 4 & $(3-3) 2+(4-7) 2=9$ \\
\hline 1 & 4 & $(1-3) 2+(4-7) 2=13$ \\
\hline
\end{tabular}

Menentukan jarak dan menentukan tetangga paling dekat berdasarkan pada jarak minimum seperti pada table 2.3 berikut :

Tabel 2.3 Pengurutan jarak terdekat

\begin{tabular}{|c|c|l|l|l|}
\hline X1 & X2 & $\begin{array}{l}\text { Kuadrat } \\
\text { Absolute } \\
\text { Distance } \\
(3,7)\end{array}$ & $\begin{array}{l}\text { Peringkat } \\
\text { Minimum } \\
\text { Distance }\end{array}$ & $\begin{array}{l}\text { Termasuk } \\
\text { K/3- } \\
\text { Nearest } \\
\text { Neighbour? }\end{array}$ \\
\hline 7 & 7 & 16 & 3 & Ya \\
\hline 7 & 4 & 25 & 4 & Tidak \\
\hline 3 & 4 & 9 & 1 & Ya \\
\hline 1 & 4 & 13 & 2 & Ya \\
\hline
\end{tabular}

Mengumpulkan kategori y yang menyangkut tetangga yang paling dekat, kemudian beri pesan dalam kolom berikutnya bahwa katagori tetangga paling dekat (y) tidak dimasukkan sebab rangking data lebih dari $3(\mathrm{~K}=3)$ seperti pada table 2.4.

Tabel 2.4 Penentuan tetangga terdekat

\begin{tabular}{|c|c|l|l|l|l|}
\hline X1 & X2 & $\begin{array}{l}\text { Kuadrat } \\
\text { Absolute } \\
\text { Distance } \\
(3,7)\end{array}$ & $\begin{array}{l}\text { Pering } \\
\text { kat } \\
\text { Minim } \\
\text { um } \\
\text { Distan } \\
\text { ce }\end{array}$ & $\begin{array}{l}\text { Terma } \\
\text { suk K / } \\
\text { 3-NN? }\end{array}$ & $\begin{array}{l}\text { Katego } \\
\text { ri } \\
(y)\end{array}$ \\
\hline 7 & 7 & 16 & 3 & Ya & Buruk \\
\hline 7 & 4 & 25 & 4 & Tidak & - \\
\hline 3 & 4 & 9 & 1 & Ya & Baik \\
\hline 1 & 4 & 13 & 2 & Ya & Baik \\
\hline
\end{tabular}

Hitung mayoritas y (kategori Nearest Neighbour) sebagai nilai ramalan dari query instance yang mempunyai kondisi 2 Baik dan 1 Buruk. Oleh karena perbandingan baik lebih besar dari buruk $(2>1)$, maka dapat disimpulkan bahwa data uji yang baru dengan $\mathrm{X}_{1}=3$ dan $\mathrm{X}_{2}=7$ adalah baik.

\section{Perancangan Perangkat Lunak}

Sistem Analisis Gaya Belajar Menggunakan Algoritma K-Nearest Neighbour adalah sistem yang 
dapat menganalisis gaya belajar berdasarkan peryataan-pernyataan yang berisi parameter gaya belajar tertentu yang sesuai dengan karakter individu. Dari sistem ini akan diketahui gaya belajar yang dominan serta cara belajar yang cocok untuk individu yang bersangkutan dengan cara membandingkan data uji dengan training data set menggunakan algoritma K-Nearest Neighbour. Training data set diperoleh dari penelitan yang dilakukan Bella Hening Hukama (2011) dengan judul "Inventori Gaya Belajar Siswa Sekolah Dasar Berbasis Komputer dengan Menggunakan Software" yang hasil analisisnya dilakukan dengan menggunakan penormaan pada setiap parameternya yang dihitung menggunakan rumus Alpha Cronbac.

a. Perancangan Use Case

Terdapat 2 aktor yang terlibat dalam use case diagram sistem analisis gaya belajar ini yaitu peserta dan admin yang ditunjukkan pada gambar 3.1 berikut.

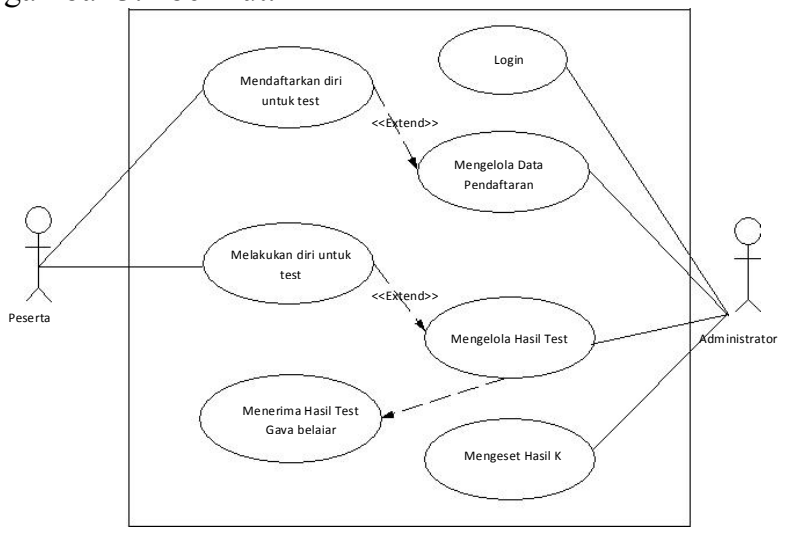

Gambar 3.1 Use Case Diagram

b. Perancangan Basis Data

Diagram Entity Relationship menggambarkan hubungan entitas satu dengan lainnya. Secara umum diagram Entity Relationship dari struktur basis data pada Sistem Analisis Gaya Belajar yang ditunjukkan pada gambar 3.2 berikut.

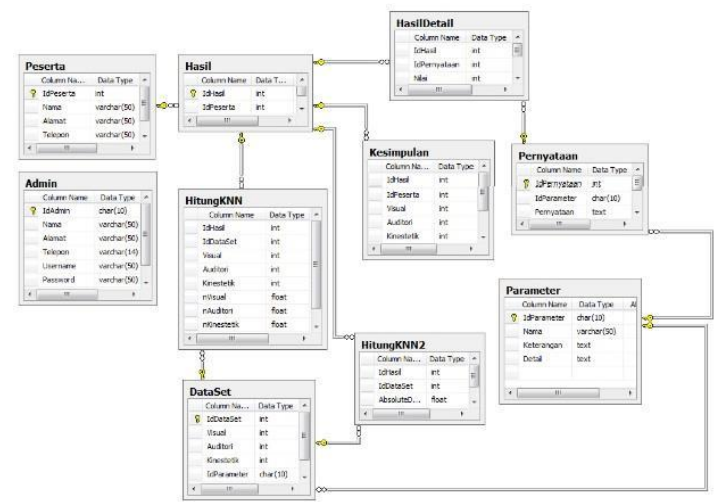

Gambar 3.2 Diagram Database c. Perancangan Antarmuka

1. Spash Screen

Merupakan form yang pertama kali muncul ketika aplikasi dijalankan. Form ini berisi tentang pangantar gaya belajar dan penjelasan singkat tentang aplikasi seperti gambar 3.3 berikut.

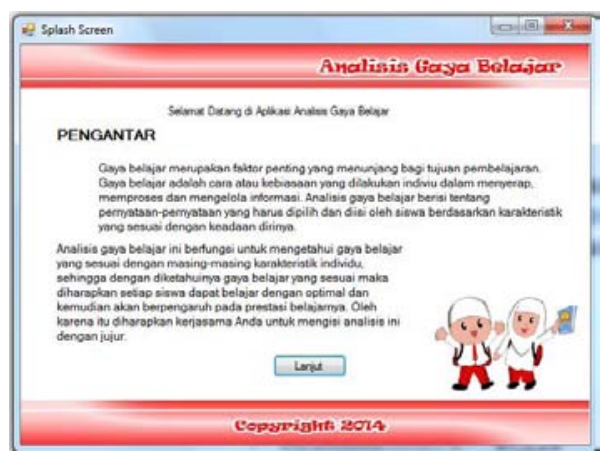

Gambar 3.3 Splash Screen

2. Form Utama

Merupakan form menu utama dari aplikasi. Terdapat dua pilihan menu yaitu peserta dan admin. Menu peserta digunakan untuk peserta yang akan melakukan tes.

Sedangkan menu admin digunakan administrator untuk mengelola data peserta, data admin, dan hasil analisis gaya

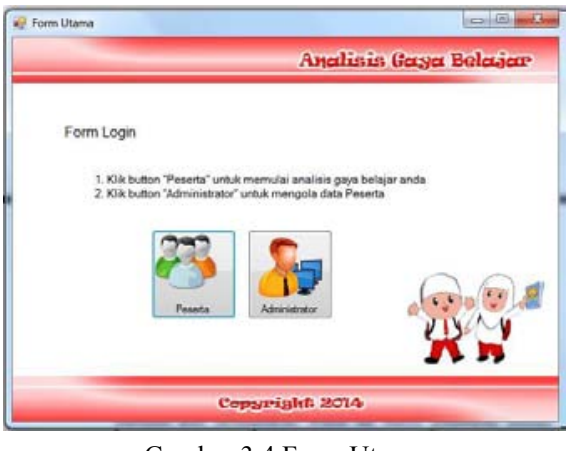

Gambar 3.4 Form Utama

3. Form Pernyataan

Peserta harus menjawab semua pernyataan yang sudah disediakan oleh sistem seperti berikut ini.

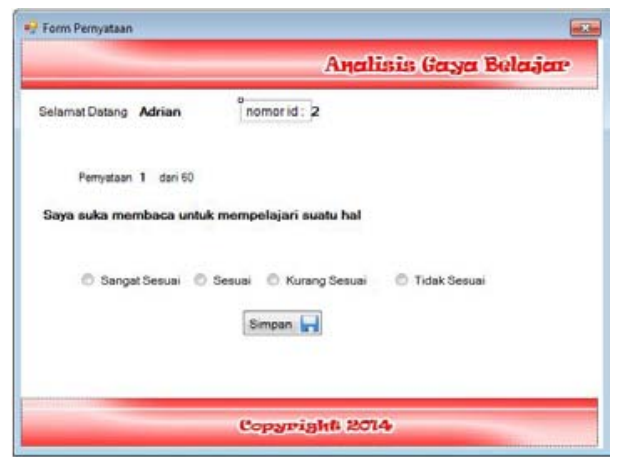




\section{Hasil}

Setelah peserta menjawab semua pernyataan, maka sistem akan mengeluarkan hasilnya seperti berikut ini.

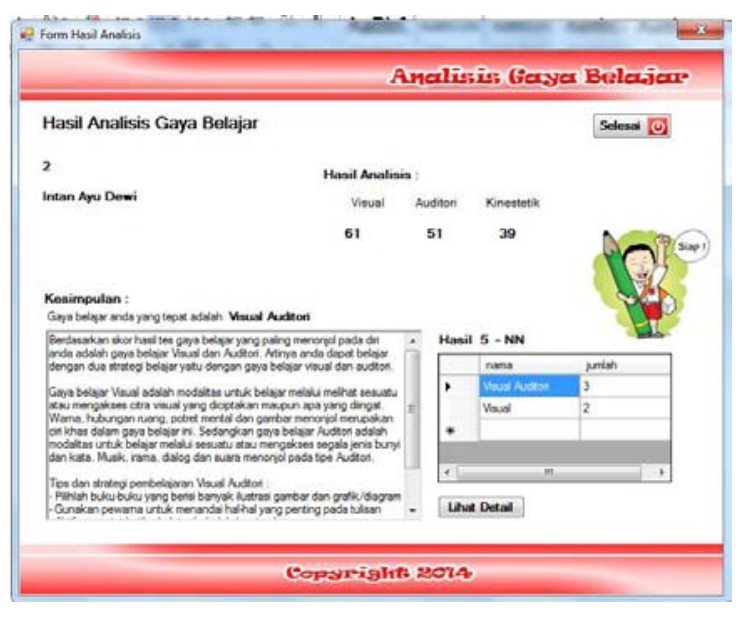

Gambar 4.1 Form Utama

\section{Pembahasan}

Dari hasil percobaan, diperoleh hasil visual $=$ 61, auditori $=59$ dan kinestetik $=42$. Pada percobaan ini nilai K yang digunakan adalah 6 .

Dalam sistem dataset sebanyak 250 dihitung menggunakan perhitungan KNN, data dibagi menjadi 2 bagian yaitu 100 data digunakan untuk menganalisis hasil dari percobaan dan 150 data lainnya digunakan sebagai data banding. Berikut ini pada tabel 5.1 adalah contoh 10 dari 250 data latih.

\section{Tabel 5.1 Data Latih}

\begin{tabular}{|c|c|c|c|l|}
\hline No & Vis & Aud & Kin & \multicolumn{1}{|c|}{ Kesimpulan } \\
\hline 1 & 58 & 50 & 49 & Visual dan Auditori \\
\hline 2 & 65 & 57 & 50 & Visual \\
\hline 3 & 67 & 65 & 48 & Visual dan Auditori \\
\hline 4 & 70 & 69 & 44 & Visual dan Auditori \\
\hline 5 & 47 & 58 & 41 & Auditori \\
\hline 6 & 71 & 62 & 36 & Visual dan Auditori \\
\hline 7 & 68 & 68 & 38 & Visual dan Auditori \\
\hline 8 & 68 & 63 & 42 & Visual dan Auditori \\
\hline 9 & 68 & 47 & 45 & Visual \\
\hline 10 & 57 & 54 & 52 & $\begin{array}{l}\text { Visual, Auditori dan } \\
\text { Kinestetik }\end{array}$ \\
\hline
\end{tabular}

Langkah selanjutnya adalah menghitug jarak absolutnya antara data uji dengan semua data latih yang digunakan. Contoh 10 dari 100 data latih yang digunakan.

Tabel 5.2 Perhitungan Absolute Distance

\begin{tabular}{|l|l|l|l|}
\hline Vis & Aud & Kin & $\begin{array}{l}\text { Kuadrat Absolute Distance } \\
(61,59,42)\end{array}$ \\
\hline 58 & 50 & 49 & $(58-61) 2+(50-59) 2+(49-42) 2+=139$ \\
\hline 65 & 57 & 50 & $(65-61) 2+(57-59) 2+(50-42) 2+=84$ \\
\hline 67 & 65 & 48 & $(67-61) 2+(65-59) 2+(48-42) 2+=108$ \\
\hline 70 & 69 & 44 & $(70-61) 2+(69-59) 2+(44-42) 2+=185$ \\
\hline 47 & 58 & 41 & $(47-61) 2+(58-59) 2+(41-42) 2+=198$ \\
\hline
\end{tabular}

\begin{tabular}{|l|l|l|l|}
\hline 71 & 62 & 36 & $(71-61) 2+(62-59) 2+(36-42) 2+=145$ \\
\hline 68 & 68 & 38 & $(68-61) 2+(68-59) 2+(38-42) 2+=146$ \\
\hline 68 & 63 & 42 & $(68-61) 2+(63-59) 2+(42-42) 2+=65$ \\
\hline 68 & 47 & 45 & $(68-61) 2+(47-59) 2+(45-42) 2+=202$ \\
\hline 57 & 54 & 52 & $(57-61) 2+(54-59) 2+(52-42) 2+=141$ \\
\hline
\end{tabular}

Langkah berikutnya adalah mengurutkan hasil perhitungan berdasarkan nilai kuadrat absolute distance dari nilai yang terkecil hingga yang terbesar seperti pada tabel 5.3 berikut.

Tabel 5.3 Pengurutan berdasarkan Absolute Distance

\begin{tabular}{|c|c|c|c|l|}
\hline Vis & Aud & Kin & $\begin{array}{r}\text { Abs } \\
\text { Dist }\end{array}$ & \multicolumn{1}{|c|}{ Kesimpulan } \\
\hline 58 & 65 & 45 & 54 & Auditori \\
\hline 68 & 63 & 42 & 65 & Visual dan Auditori \\
\hline 56 & 65 & 45 & 70 & Auditori \\
\hline 65 & 57 & 50 & 84 & Visual \\
\hline 56 & 52 & 47 & 99 & Visual dan Auditori \\
\hline 60 & 50 & 47 & 107 & Visual dan Auditori \\
\hline 67 & 65 & 48 & 108 & Visual dan Auditori \\
\hline 59 & 66 & 50 & 117 & Auditori \\
\hline 56 & 51 & 49 & 138 & Visual dan Auditori \\
\hline 58 & 50 & 49 & 139 & Visual dan Auditori \\
\hline 57 & 54 & 52 & 141 & Visual, Auditori, Kinestetik \\
\hline 71 & 62 & 36 & 145 & Visual dan Auditori \\
\hline
\end{tabular}

Setelah data perhitungan diurutkan berdasarkan nilai jarak absolutnya, langkah selanjutnya adalah mengambil dan mengelompokkan data hasil perhitungan yang telah diurutkan berdasarkan nilai $\mathrm{K}$ yang telah ditentukan. Dalam percobaan kali ini, $\mathrm{K}$ yang digunakan adalah $6(\mathrm{~K}=6)$

Tabel 5.4 Pengurutan dan Pengelompokan Data Berdasarkan Nilai K

\begin{tabular}{|c|c|c|c|l|}
\hline Vis & Aud & Kin & $\begin{array}{c}\text { Kuadrat } \\
\text { Absolute } \\
\text { Distance }\end{array}$ & \multicolumn{1}{|c|}{ Kesimpulan } \\
\hline 58 & 65 & 45 & 54 & Auditori \\
\hline 68 & 63 & 42 & 65 & Visual dan Auditori \\
\hline 56 & 65 & 45 & 70 & Auditori \\
\hline 65 & 57 & 50 & 84 & Visual \\
\hline 56 & 52 & 47 & 99 & Visual dan Auditori \\
\hline 60 & 50 & 47 & 107 & Visual dan Auditori \\
\hline
\end{tabular}

Dari 6 hasil perhitungan dengan nilai jarak absolutnya terkecil, maka dihitung kesimpulannya berdasarkan parameter. Dari tabel diatas diperoleh hasil perhitungan KNN.

Tabel 5.5 Hasil Perhitungan KNN

\begin{tabular}{|l|c|}
\hline \multicolumn{1}{|c|}{ Parameter } & Total \\
\hline Visual & 1 \\
\hline Auditori & 2 \\
\hline Kinestetik & 0 \\
\hline Visual dan Auditori & 3 \\
\hline Visual dan Kinestetik & 0 \\
\hline Auditori dan Kinestetik & 0 \\
\hline Visual, Auditori dan Kinestetik & 0 \\
\hline
\end{tabular}


Maka dapat disimpulkan bahwa untuk data uji Visual $=61$, Auditori $=59$ dan Kinestetik $=42$ dengan nilai $(\mathrm{K}=6)$ adalah Visual dan Auditori.

Dari hasil perhitungan menggunakan 250 dataset, maka hasil perhitungan KNN dibandingkan dengan 150 dataset lainnya untuk mengetahui validitas hasil perhitungan dari hasil percobaan diperoleh perbandingan data sebagai berikut.

Tabel 5.6 Perbandingan Hasil KNN

\begin{tabular}{|r|r|r|l|l|}
\hline \multirow{2}{*}{ Vis } & \multirow{2}{*}{ Aud } & \multirow{2}{*}{ Kin } & \multicolumn{2}{|c|}{ Kesimpulan } \\
\cline { 4 - 5 } & 51 & 42 & $\begin{array}{l}\text { Disual dan } \\
\text { Auditori }\end{array}$ & $\begin{array}{l}\text { Visual dan } \\
\text { Auditori }\end{array}$ \\
\hline
\end{tabular}

Oleh karena hasil perhitungan KNN pada data tes dan data banding untuk data uji Visual $=61$, Auditori $=59$ dan Kinestetik $=42$ dengan nilai $(\mathrm{K}=6)$ nilainya sama, yaitu Visual dan Auditori, maka dapat disimpulkan bahwa hasil analisis KNN untuk data uji tersebut benar.

Dalam aplikasi, perhitungan KNN terhadap data uji dapat dilihat dalam form detail perhitungan KNN seperti pada gambar berikut.

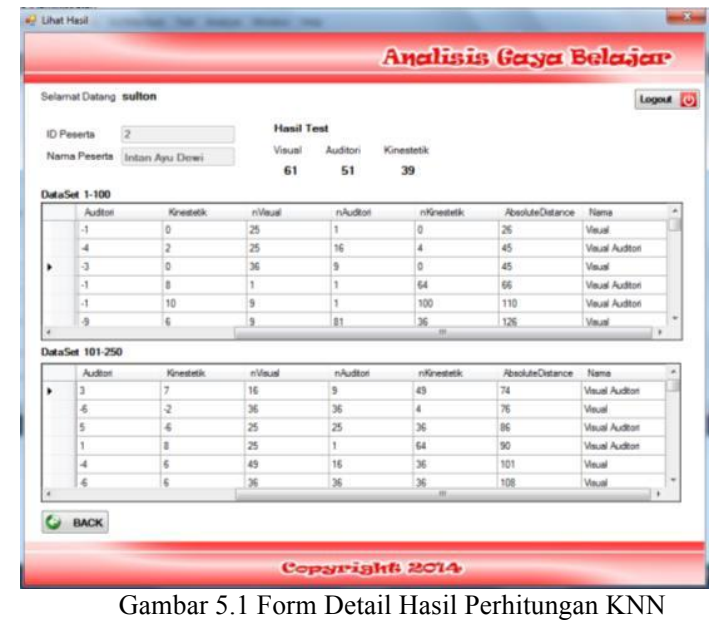

Sedangkan kesimpulan hasil analisis data uji, dapat dilihat di form hasil analisis seperti pada gambar berikut.

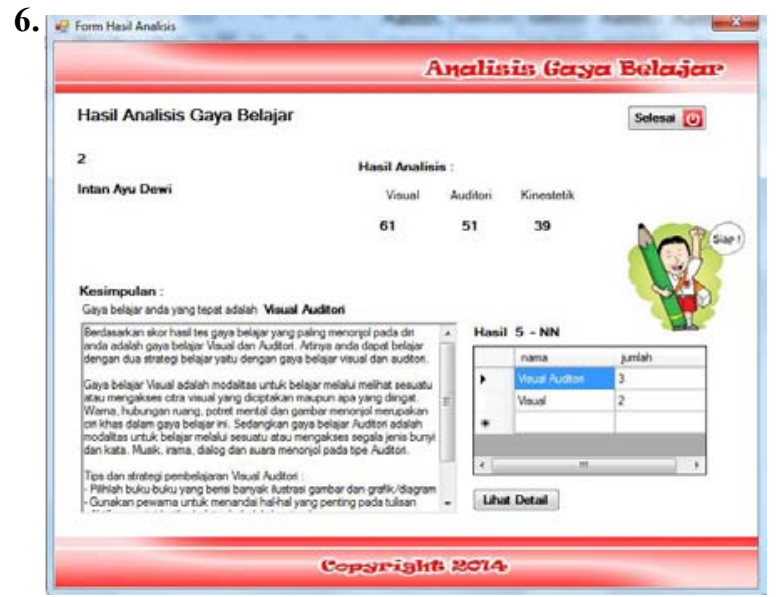

Gambar 5.2 Form Hasil Analisis Gaya Belajar

\section{Kesimpulan dan Saran}

Kesimpulan dari hasil penelitian yang telah dilakukan antara lain :

1. Algoritma KNN dapat diimplementasikan untuk menganalisis gaya belajar dengan akurasi $88 \%$.

2. Nilai $\mathrm{K}$ yang paling optimal dalam kasus ini adalah $\mathrm{K}=9$ dengan akurasi algoritma sebanyak $88 \%$.

3. Error banyak terjadi ketika kesimpulan dari data uji merupakan paramter gabungan. Dalam penelitian ini, error terbesar adalah ketika menentukan kesimpulan dari data uji yang mempunyai parameter gabungan antara visual, auditori dan kinestetik.

Saran dari penulis untuk penelitian selanjutnya antara lain :

1. Sebaran dataset sebaiknya dibuat rata agar hasil yang diperoleh dari perhitungan $\mathrm{KNN}$ lebih akurat.

2. Diperlukan perhitungan lanjutan ketika data jumlah parameter yang muncul dalam kesimpulan sama sehingga membuat kesimpulan yang dibuat lebih tepat.

\section{Daftar Pustaka :}

Susilo, M. Joko. 2006. Gaya Belajar Menjadikan Makin Pintar. Yogyakarta: Pinus Book Publisher.

Hermawati, Fajar Astuti. 2013. Data Mining. Yogyakarta: Andi Publisher

Kristanto Harianto. 2004. Konsep \& Perancangan Database. Yogyakarta: Andi Publisher.

Nugroho Aryo. 2009. SQL Server 2008. Jakarta: PT. Elex Media Komputindo.

Kusrini; Emha Taufiq Luthfi. 2009. Algoritma Data Mining. Jogjakarta: Andi Publisher.

Hasan Iqbal. 2004. Analisis Data Penelitian Dengan Statistik. Jakarta: PT. Bumi Aksara

Fathansyah, Ir. 2002. Basis Data. Bandung: Informatika.

Samples, Bob. 2002. Revolusi Belajar untuk Anak. Bandung: Kaifa.

Saputra, Sigit A. 2012. Visual Basic 2010 Programming. Yogyakarta: Andi Publisher kerjasama dengan Wahana Komputer

Nasution, S. 1988. Berbagai Pendekatan dalam Proses Belajar Mengajar. Cetakan ke-4. Jakarta: PT. Bina Aksara.

Dwipriyatmoko. 2011. Pengembangan Aplikasi Learning Style Inventory Berbasis Fuzzy Logic untuk Menentukan Gaya Belajar. Skripsi Sarjana Universitas Negeri Malang.

Hening Hukama, Bella. 2011. Inventori Gaya Belajar Siswa Sekolah Dasar Berbasis Komputer dengan Menggunakan Software. Skripsi Sarjana Universitas Negeri Malang. 
http://educate.intel.com/id/ProjectDesign/Thinking

Skills/ThinkingFrameworks/Learning_Styles.h tm.

Gaya Belajar. Diakses tanggal 21 April 2014.

http://people.revoledu.com/kardi/tutorial/KNN/inde

x.html. Algoritma K-Nearest Neighbour. Diakses

tanggal 27 April 2014. 